\title{
ANÁLISE ERGONÔMICA DE UM PRODUTO DE CONSUMO: O CASO DE UM BEBEDOURO DE MESA TIPO GELÁGUA
}

\section{ERGONOMIC ANALYSIS OF A CONSUMPTION PRODUCT: THE CASE OF A GELAGUA TABLE DRINK}

\author{
Alaíde Farias, Enfermeira (1); \\ Marilande Silva, Enfermeira (2); \\ Waldelourdes de Melo, Enfermeira (3); \\ Marcelo Soares, Ph.D. em ergonomia (4); \\ 1. Universidade Federal de Pernambuco \\ E-mail: alaideff@hotmail.com \\ 2. Universidade Federal de Pernambuco \\ E-mail: marilande_andrade@ @otmail.com \\ 3. Universidade Federal de Pernambuco \\ E-mail: walmelosoutomaior@gmail.com \\ 4. Universidade Federal de Pernambuco \\ E-mail: soaresmm@gmail.com
}

Palavras-chave: Ergonomia; produto de consumo; bebedouro.

Este artigo relata a avaliação ergonômica de um bebedouro. Foram feitas entrevistas para avaliar a satisfação dos usuários. Para fundamentação, aplicamos a etapa de apreciação do sistema humano-tarefa-máquina (Moraes e Mont'Alvão (2000); para delinearmos as características do design, fizemos uma análise de acordo com os princípios de usabilidade de Jordan (1998).

Keywords: Ergonomics; Consumer product; drinking fountain. 
This article reports the ergonomic evaluation of a drinking fountain. Interviews were conducted to assess user satisfaction. In order to explain the characteristics of the design, we performed an analysis according to the usability principles of Jordan (1998).

\section{Introdução}

A água é um recurso natural de suma importância para a existência dos organismos, seu fornecimento em quantidade e qualidade é fundamental para a perfeita manutenção da vida humana (PEZZARINO, 2010).

Bebedouros são produtos de consumo de extrema necessidade em diversos ambientes públicos e privados, porém a maioria deles possuem deficiências quanto a ergonomia, acessibilidade e usabilidade (DANTAS et al, 2010)

Os produtos são considerados como meios para que o homem possa executar determinadas funções. Esses produtos passam a fazer parte de sistemas homem-máquina-ambiente. Nesse contexto, o objetivo da ergonomia é estudar esses sistemas, para que as máquinas e ambientes possam funcionar harmoniosamente com o homem, de modo que o desempenho dos mesmos seja adequado (IIDA, 2005).

De acordo com os princípios de usabilidade de Jordan (1998), foi feito a classificação do produto em estudo, seguido da análise da segurança durante seu uso.

De um modo geral, Iida e Guimarães (2016), consideram que os produtos devem ser "amigáveis", fáceis de entender e fáceis de operar.

\section{Objetivo}

Analisar ergonomicamente um produto de consumo, o bebedouro de mesa tipo gelágua de marca Esmaltec, modelo EGM 30.

\section{Metodologia}

O presente artigo é de cunho descritivo-exploratório e quanti-qualitativo. Após a pesquisa bibliográfica, fizemos a problematização do Sistema HumanoTarefa-Máquina, ilustrando a categorização dos problemas ergonômicos, as atividades de uso, os atributos ergonômicos no design do produto e os parâmetros ergonômicos, bem como o design e os tipos de pegas apropriadas para o seu uso. Utilizamos parte da metodologia de Moraes e Mont'Alvão (2000), onde aplicamos a etapa de apreciação das disfunções do Sistema HumanoTarefa-Máquina (STHM), a representação esquemática das interações entre os elementos de um sistema humano-tarefa-máquina; o fluxograma funcional ação-decisão, onde apresentamos a análise da principal tarefa do bebedouro, que é dispensar água. Delineamos as características do design associadas à usabilidade do produto de acordo com os princípios de usabilidade de Jordan (1998). Também foi feita a classificação do produto em estudo, seguida da análise da segurança durante o seu uso.

\section{Apresentação do produto}

4.1 IDENTIFICAÇÃO: Bebedouro de mesa tipo gelágua Esmaltec EGM30

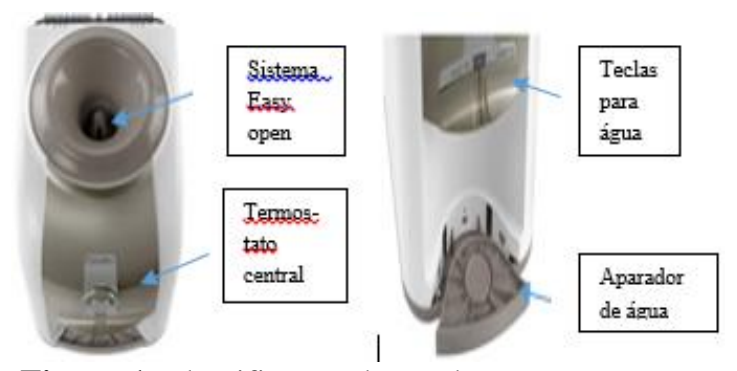

Figura 1. Identificação do produto Fonte: Manual de instruções Esmaltec

\subsection{Funções:}

O produto em estudo apresenta função Mix (permite a mistura de água natural e gelada com apenas um toque), e a refrigeração da água é feita por meio de um compressor.

\subsection{Características e especificações Técnicas do Produto}

\begin{tabular}{|l|l|}
\hline Características \\
\hline Cor & Branco \\
\hline Aprovado pelo INMETRO & Sim \\
\hline Capacidade & $3 \mathrm{~L}$ \\
\hline
\end{tabular}


$16^{\circ}$ Ergodesign - Congresso Internacional de Ergonomia e Usabilidade de Interfaces Humano Tecnológica: Produto, Informações Ambientes Construídos e Transporte

$16^{\circ}$ USIHC - Congresso Internacional de Ergonomia e Usabilidade de Interfaces Humano Computador

CINAHPA | 2017 - Congresso Internacional de Ambientes Hipermídia para Aprendizagem.

\begin{tabular}{|l|l|}
\hline Fácil instalação & Sim \\
\hline Modelo & Mesa \\
\hline Tipo de refrigeração & Compressor \\
\hline Ajuste/controle de temperatura & Sim \\
\hline Silencioso & Sim \\
\hline Indicadores luminosos & Não \\
\hline Jato de água direcionável & Não \\
\hline Ligado à rede de água & Não \\
\hline Ozonizador, Purificador & Não \\
\hline Garantia & 12 meses \\
\hline Especificações Técnicas & \\
\hline Peso & $12,5 \mathrm{Kg}$ \\
\hline Altura & $420 \mathrm{~mm}$ \\
\hline Largura & $280 \mathrm{~mm}$ \\
\hline Profundidade & $410 \mathrm{~mm}$ \\
\hline Capacidade do reservatório & $10 \mathrm{a} 20$ litros \\
\hline Potência & $97 \mathrm{Wats}$ \\
\hline Temperatura & 5 a $15^{\circ} \mathrm{C}$ \\
\hline Voltagem & $220 \mathrm{~V}$ \\
\hline Fácil limpeza & SIM \\
\hline Tipo de água (natural/gelada) & Natural e gelada \\
\hline Tipo do bebedouro & Compressor \\
\hline Consumo aproximado de energia & $0,054 \mathrm{kw} / \mathrm{h}$ \\
\hline Comprimento & $41.2 \mathrm{~cm}$ \\
\hline & \\
\hline
\end{tabular}

Figura 2. Quadro de características e especificações técnicas

\section{Problematização do sistema humano-tarefa- máquina}

A delimitação do sistema alvo com a caracterização do sistema humano-tarefa e posição serial do sistema, compreendem todos os requisitos, entradas e saídas com relação a tarefa do usuário de como todo o sistema é alimentado desde a colocação do garrafão sobre o bebedouro, verificação de existência de energia elétrica, dispensação de água e até a verificação da água. A figura abaixo representa esquematicamente a categorização e posição serial do sistema alvo, que é o bebedouro.

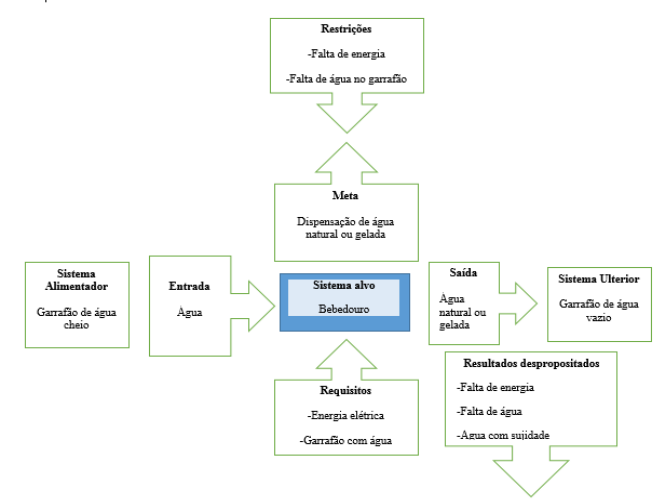

Figura 3. Caracterização e posição serial do SHTM do Bebedouro

\subsection{Categorização dos problemas ergonômicos}

A partir da observação do usuário realizando a tarefa de beber água, complementamos o processo de problematização e podemos visualizar e analisar de maneira objetiva os problemas interfaciais, de acessibilidade, informacionais e instrumentais.

\begin{tabular}{|l|l|}
\hline Problemas & Caracterização \\
\hline Interfacias & $\begin{array}{l}\text { Na etapa da tarefa de beber água o } \\
\text { anglo de visão do percentil maior } \\
(97,5 \%) \text { está fora do alcance do } \\
\text { usuário, o que poderá prejudicá-lo } \\
\text { devido a má postura ao realizar esta } \\
\text { etapa da tarefa. }\end{array}$ \\
\hline Acessibilidade & $\begin{array}{l}\text { O painel de informação do } \\
\text { bebedouro não contém braile nas } \\
\text { teclas natural/gelada, dificultando a } \\
\text { tomada de informações de } \\
\text { acionamentos por usuários } \\
\text { portadores de deficiência visual. }\end{array}$ \\
\hline $\begin{array}{l}\text { Informacionais/ } \\
\text { visuais }\end{array}$ & $\begin{array}{l}\text { A ausência de signos visuais } \\
\text { dificulta a fácil interação da } \\
\text { interação com seus usuários. }\end{array}$ \\
\hline Instrumentais & $\begin{array}{l}\text { O espaço entre as teclas de água } \\
\text { natural/gelada e o aparador de água } \\
\text { é muito curto, impedindo assim que } \\
\text { o usuário utilize copos de diversos } \\
\text { tamanhos. }\end{array}$ \\
\hline
\end{tabular}

Figura 4. Quadro de caracterização dos problemas ergonômicos

\section{- Disfunções ergonômicas}

A principal disfunção ergonômica constatada durante a análise deste produto foi de natureza interfacial, consistindo na má postura durante a realização da tarefa.

\section{- Disfunções do elemento máquina}

As disfunções do bebedouro foram levantadas fundamentadas nas observações feitas a partir dos usuários e da observação ao produto:

Desempenho do sistema e confiabilidade, consistindo na deficiência do desempenho quando não atinge a capacidade no que tange à eficiência, qualidade e conformidade. 
$16^{\circ}$ Ergodesign - Congresso Internacional de Ergonomia e Usabilidade de Interfaces Humano Tecnológica: Produto, Informações Ambientes Construídos e Transporte

$16^{\circ}$ USIHC - Congresso Internacional de Ergonomia e Usabilidade de Interfaces Humano Computador

CINAHPA | 2017 - Congresso Internacional de Ambientes Hipermídia para Aprendizagem.

O bebedouro não é bivolt, o que causa problema de usar o produto em lugares em que a voltagem é diferente;

Não há compartimento para arrumação do fio no bebedouro deixando-o sempre exposto e desarrumado.

\section{Atividades de uso}

\subsection{Modelo operacional do Sistema Humano Máquina}

Esta fase é representada com a transmissão de informação, compreendendo os subsistemas humanos de tomada de informação/percepção (sentidos humanos envolvidos); os subsistemas humanos de resposta/regulação (ações realizadas); os subsistemas da máquina que fornecem informações para serem processadas pelo homem e os subsistemas da máquina que recebem as ações do homem (MORAES; MONT'ALVÃO, 2012).

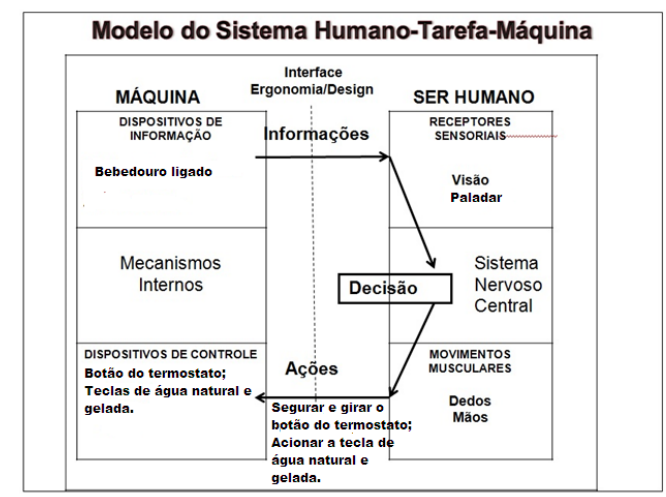

5. Modelagem comunicacional do Sistema Humano Máquina

A figura acima se refere à sucessão das informações/operações, através de fontes de interação, com a utilização do sistema humano na tomada das decisões implicadas pelos sentidos humanos envolvidos (visão e paladar), as respostas humanas e os componentes acionais (sistema máquina), informações fornecidas pela máquina para o ser humano durante a realização da tarefa.

\subsection{Alocação de funções e tarefas}

Nesta fase foi elaborado um quadro com as diversas funções do equipamento, discriminando as funções e tarefas melhor desempenhadas pelo humano e pela máquina.

\begin{tabular}{|l|l|}
\hline Funções e Tarefas & $\begin{array}{l}\text { Melhor } \\
\text { desempenho }\end{array}$ \\
\hline Escolher o comando no painel & Humano \\
\hline Beber água natural ou gelada & Humano \\
\hline Colocar o copo no dispensador de água & Humano \\
\hline Programar a temperatura da água & Humano \\
\hline Ligar/Desligar a máquina & Humano \\
\hline Tirar a água da máquina & Humano \\
\hline Colocar garrafão de água no bebedouro & Humano \\
\hline Gelar a água & Máquina \\
\hline Controlar a temperatura da água & Máquina \\
\hline
\end{tabular}

Figura 6. Quadro de alocação de funções

\subsection{Análise da tarefa}

Esta fase incluiu o conhecimento e a ordenação das atividades da tarefa e a construção de um fluxograma de atividades.

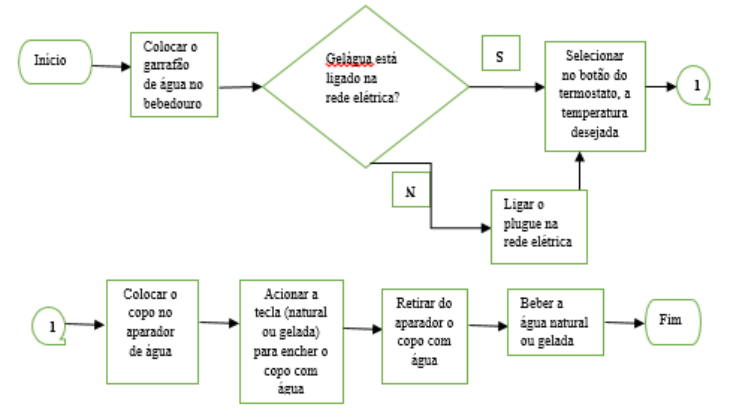

Figura 7. Fluxograma funcional ação decisão (tarefa beber água)

Neste fluxograma encontra-se ilustrada a análise da tarefa (beber água), utilizando-se o produto bebedouro de mesa tipo gelágua.

\subsection{Identificação e análise dos atributos ergonômicos no design do produto.}

SEGURANÇA: O plugue oferece proteção ao usuário por já ter um adaptador para ligá-lo na tomada.

EFICIÊNCIA: O produto é eficiente, uma vez que atende a sua proposta inicial, que é gelar a água.

SATISFAÇÃO NO USO: Os usuários demonstramse satisfeitos com o gelágua. O manuseio é simples, basta seguir o Manual de Instruções.

Realização:


DURABILIDADE: O que contribui para sua durabilidade é conservá-lo em local protegido do sol ou de outro elemento abrasivo.

ADEQUAÇÃO AO USO: O bebedouro deve ser colocado em cima de um balcão ou de uma mesa ao ser utilizado para o fim ao qual se destina, para que o usuário assuma uma postura adequada, que não exige muita força física nem realize movimentos repetitivos.

PREÇO REALÍSTICO: O preço do gelágua encontra-se entre R \$390,00 a 480,00. Acredita-se que seja um preço realístico, ao compará-lo com os demais eletrodomésticos.

BOA APARÊNCIA: Em geral, o design do gelágua apresenta uma boa aparência.

\section{Análise das funções ergonômicas para o relacionamento entre o objeto de estudo e o usuário}

Segundo Lobach (2001), as funções de um produto são apresentadas como são percebidas pelo consumidor. O design atua como um método de concepção premeditada e tem como objetivo atender as necessidades propostas pelo produto.

Quanto à esfera da Usabilidade, nesta análise foram utilizadas as dimensões propostas por Kim e Han (2008), para heurísticas de usabilidade para produtos de consumo eletrônicos. Então o bebedouro foi assim analisado:

SIMPLICIDADE: O método de interação do produto com o usuário é simples, claro e intuitivo. Basta que o usuário leia as instruções.

CONSISTÊNCIA: A interface é consistente dentro do produto e entre produtos da mesma família.

CONTROLE DO USUÁRIO: O usuário tem total autoridade para controlar as funções do bebedouro.

FEEDBACK: O status do produto e as consequências de qualquer operação do usuário são fornecidas de forma clara e imediata.

MENSAGEM DE ERRO: Não se aplica ao produto em análise.

ADAPTABILIDADE: Significa que modificações da interface devem encaixar diferentes usuários e condições de acordo com a experiência, conhecimento e preferências dos mesmos. Este produto apenas oferece um roteiro único a ser seguido por todos os tipos de usuário.

ACESSIBILIDADE: Como todas as funções são facilmente visualizadas, esse produto foi considerado acessível.

CAPACIDADE DE APRENDIZADO: Pelo fato do produto ser intuitivo e das informações estarem expostas por extenso, o esforço necessário para o aprendizado do usuário é pequeno.

MEMORIZAÇÃO: Pelo fato das informações serem legíveis, o usuário tem facilidade de lembrar os métodos de interação.

FAMILIARIDADE: Este conceito está presente. Mas pela clareza de uso, é fácil associar o seu uso aos de outros produtos similares.

INFORMATIVA: A interface foi considerada de compreensão fácil e clara.

EFICÁCIA: Toda a programação está disponível, podendo ser visualizada facilmente.

EFICIÊNCIA: Este produto foi projetado para permitir que um usuário execute funções de forma fácil.

\section{Análise dos tipos de pega utilizadas no bebedouro}

As pegas foram classificadas como prênseis ou nãoprênseis.

\subsection{Posições de pegas empregadas durante a utilização do bebedouro}

Consideramos as relações mão-objeto para fazer a classificação das pegas.

8.1.1 Pega "toque de dedos" - É uma pega prênsil, utilizada para selecionar no termostato a temperatura da água.

8.1.2 Pega "palma dedos" - A forma da pega dos copos (elemento utilizado durante a realização da tarefa de beber água) tem forma anatômica, cilíndrica, encaixa bem na mão do usuário, seja ele homem ou mulher. 


\section{$16^{\circ}$ \\ ERGODESIGN USIHC CINAHPA}
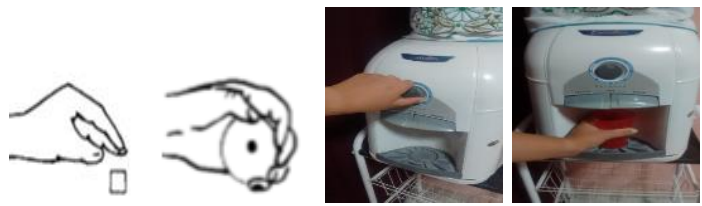

Figura 8. Tipos de pega utilizados durante a realização da tarefa.

\section{Classificação do tipo de produto e recomendações para sua configuração}

Verificamos as características físicas do bebedouro que é classificado como um produto portável. Os dados e as diretrizes para a configuração deste produto relacionam-se à dimensão do produto, forma, peso e característica de pega. $\mathrm{O}$ bebedouro atende a orientação de peso máximo recomendado para produtos que serão suspensos.

\section{Análise da segurança do produto}

Relacionamos os tipos de perigo potencial e apresentadas estratégias visando a redução desses riscos.

CHOQUE ELÉTRICO: Não ligar o bebedouro e não tocar no cabo elétrico utilizando as mãos molhadas.

\section{POSSÍVEIS DANOS AO UTILIZAR UMA TENSÃO COM VOLTAGEM DIFERENTE: \\ Certificar-se que o tipo de tensão do produto equivale ao do domicílio do usuário.}

RISCOS PARA INCÊNDIO: Não ligar o produto em tomadas elétricas com outros produtos simultaneamente.

\section{Análise de campo com usuários}

A metodologia empregada foi baseada no estudo de Sabino Neto et al. (2004), com uma adaptação ao produto em estudo. Consistiu na observação direta de 10 usuários durante a utilização do bebedouro. Cada usuário realizou a tarefa de beber água, com o intuito de verificar o funcionamento e a usabilidade percebida. Aplicamos um questionário de satisfação, e para verificar a opinião dos usuários, elaboramos perguntas com dados gerais: Idade e gênero, uso do produto, frequência de uso, qual programação costuma utilizar (água natural ou gelada), material do produto, satisfação em relação à limpeza, aspectos ergonômicos, opinião sobre o design do produto (se considera agradável, silencioso, eficaz, $16^{\circ}$ Ergodesign - Congresso Internacional de Ergonomia e Usabilidade de Interfaces Humano Tecnológica: Produto, Informações Ambientes Construídos e Transporte

$16^{\circ}$ USIHC - Congresso Internacional de Ergonomia e Usabilidade de Interfaces Humano Computador

CINAHPA | 2017 - Congresso Internacional de Ambientes Hipermídia para Aprendizagem.

seguro, se recomendaria o produto e se vivenciou algum acidente durante o uso). E como resultados: $15 \%$ eram do sexo masculino e $85 \%$ feminino, com idades de 30 a 50 anos. Em relação ao uso do produto, $95 \%$ utilizam o produto com muita frequência e selecionam água gelada. Em relação ao material do produto $90 \%$ responderam que é de fácil limpeza. Quanto aos aspectos ergonômicos, $96 \%$ consideraram agradável, eficaz, seguro e recomendariam o produto. $90 \%$ nunca sofreram acidentes durante a realização da tarefa.

\section{Conclusão}

Constatamos que o bebedouro é um produto silencioso e eficiente. Foi possível observar que a interação do usuário com o produto gira em torno da análise. Este estudo nos permitiu analisar que o bebedouro contém compressor com o poder de atingir a temperatura de água gelada e facilita a limpeza por conter peças removíveis e encaixes precisos. A interpretação desse produto é completamente atrelada às experiências vividas pelos usuários. É válido ressaltar que antes mesmo de haver o contato com o produto, é necessário saber da sua finalidade, qual é o seu objetivo e sua necessidade de utilizá-lo. Sendo assim, a sua interpretação proporcionará uma experiência de usabilidade mais adequada. Diante do exposto, espera-se que este artigo tenha contribuído para mostrar uma análise fundamentada e para melhorias nas características ergonômicas do produto, promovendo um impacto no aumento da qualidade do produto.

\section{Referências}

DANTAS, A. K. D.; SOUZA, C.; FERREIRA, M.

S.; ANDRADE, M. A.; WATANABE, E.

Qualidade microbiológica da água de bebedouros destinada ao consumo humano. Biociências, Unitau, v. 16, n. 2, 201.

ESMALTEC ELETRODOMÉSTICOS S.A.

Disponível em https//www.esmaltec.com.br. Acessado em 25/11/2016.

IIDA, I. Ergonomia: projeto e produção. 2. Ed. São Paulo: Blucher, 2005.
Realização:

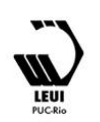


IIDA, I.; GUIMARÃES, L.B.M. Ergonomia:

Projeto e Produção. 3. Ed. São Paulo: Blucher, 2016.

JORDAN, P. W. An Introduction to Usability. Londres: Taylor \& Francis Ltda., 1998.

KIM, J.;HAN, S. H.. A methodology for developing a usability index of consumer electronic products. International Journal of Industrial Ergonomics, v. 38, p. 333-345, 2008.

LÖBACH, B. Design industrial: bases para a configuração dos produtos industriais. São Paulo: E. Blücher, 2001.

MORAES, A. de; MONT'ALVÃO, C. Ergonomia: conceitos e aplicações. Teresópolis: 2AB. 4 ed., 2012.

PEZZARINO, R da S. Avaliação da Qualidade da Água Utilizada nos Distritos de Campos dos Goytacazes, RJ. Dissertação apresentada (Mestrado em Engenharia Ambiental) IFF Campus CamposCentro, Campos dos oytacazes, RJ, 2010.

SABINO NETO, A.C.S. Melhoria de produtos de uso doméstico com a aplicação da ergonomia integrada ao processo de projeto. XXIV Encontro Nacional de Engenharia de Produção. Florianópolis, SC, 03 a 05 de novembro de 2004. 